\title{
CORÍNDON NO BRASIL: QUÍMICA, INCLUSÕES, ESPECTROSCOPIA E ASPECTOS GENÉTICOS
}

\author{
ANTONIO LICCARDO ${ }^{1}$, HANNA JORDT-EVANGELISTA ${ }^{2} \&$ ESTER FIGUEIREDO OLIVEIRA ${ }^{3}$
}

\begin{abstract}
Resumo A investigação das características mineralógicas e químicas de coríndon de onze depósitos no Brasil objetivou contribuir para o entendimento da gênese e para obter um acervo de dados que constituam "assinaturas" na elucidação da procedência em amostras desconhecidas. Na maioria dos depósitos coríndon é recuperado de sedimentos recentes, exceto em dois casos onde é encontrado na rocha hospedeira. Elementos-traços foram analisados por INAA e ICP-OES, inclusões sólidas por MEV-EDS e espectros de absorção foram obtidos na faixa do UV-Visivel. Os elementos-traços mais importantes considerados na discussão da causa da cor e/ou da gênese são ETR, Th, Ga, Fe, Ti, Cr, W, Sb, La e Ta. Formação por metamorfismo de alto grau em rochas metassedimentares aluminosas é sugerida para coríndon da maioria dos depósitos (Catingal e Lajedinho - BA, Palmeiras, Sapucaia, Indaiá e Caputira - MG) conforme indicado pelo contexto geológico, inclusões minerais e/ou química. Em Peixe (TO), coríndon em pegmatitos é magmático. Nos depósitos secundários de Malacacheta e Campo Belo (MG), Coxim (MS) e Barra Velha (SC) a gênese do coríndon é incerta ou devida, possivelmente, à interação de processos metamórficos e metassomáticos.
\end{abstract}

Palavras-chave: coríndon, Brasil, elementos-traços, INAA, inclusões, UV-Visível, gênese

\begin{abstract}
CORUNDUMFROM BRAZIL CHEMISTRY, INCLUSIONS, SPECTROSCOPY AND CONSTRAINTS ON THE GENESIS INVESTIGATION Investigation of mineralogical and chemical characteristics of corundum from eleven deposits in Brazil aimed to contribute to the understanding of genesis and to obtain a set of data to be used as a fingerprint to elucidate provenience of unknown samples. In most deposits corundum is recovered from recent sediments except in two cases where it is found in the host rock. Trace-elements were analyzed by INAA and ICP-OES, solid inclusions by SEM-EDS and absorption spectra were obtained in the range of UV - visible. The most important trace-elements considered in the discussion of cause of color and/or genesis are REE, Th, Ga, Fe, Ti, Cr, W, Sb, La, and Ta. Formation by high-grade metamorphism in aluminous metasedimentary rocks is suggested for corundum from most deposits (Catingal and Lajedinho - BA, Palmeiras, Sapucaia, Indaiá and Caputira - MG) as indicated by geological context, mineral inclusions and/or chemistry. In Peixe (TO), corundum hosted in pegmatite is magmatic. In the secondary deposits of Malacacheta and Campo Belo (MG), Coxim (MS), and Barra Velha (SC) the genesis of corundum is unclear or possibly due to the interaction of metamorphic and metassomatic processes.
\end{abstract}

Keywords: corundum, Brazil, trace-elements, INAA, inclusions, UV-Visible, genesis

\begin{abstract}
INTRODUÇÃO E ASPECTOS GEOLÓGICOS A gênese do coríndon é usualmente associada a rochas metamórficas de alto grau, a processos metassomáticos ou a cristalização em complexos alcalinos e álcali-basálticos. Em $80 \%$ dos depósitos no mundo, o mineral é encontrado em depósitos secundários, como aluviões, pláceres e colúvios (Hughes, 1990), o que dificulta a investigação de sua origem. O estudo dos minerais pesados associados, das inclusões sólidas e da composição química, especialmente os elementos traços (Schwarz \& Stern 2000, Sutherland \& Schwarz 2001), têm sido as principais ferramentas utilizadas para essa investigação.
\end{abstract}

Coríndon é composto essencialmente por óxido de alumínio, sendo que outros elementos, contidos na forma de "impurezas", são os responsáveis pela variação de cor e refletem o processo geológico/geoquímico que deu origem ao mineral. $\mathrm{O}$ coríndon no Brasil, grande produtor de outros minerais-gemas, é ainda pouco conhecido, com ocorrências esparsas e inexploradas. Este trabalho apresenta os resultados de estudos geológicos, mineralógicos, químicos e espectroscópicos do coríndon proveniente de onze ocorrências brasileiras.

Localizados nas cinco grandes regiões brasileiras (Figura 1), os depósitos estudados são:

- Palmeiras, Caputira, Campo Belo, Sapucaia, Indaiá, e Malacacheta, na região sudeste, Estado de Minas Gerais, sendo que nas três últimas há incipiente explotação de safiras.

- Barra Velha, na região sul, Estado de Santa Catarina, com pro- dução de rubi e safira rosa de qualidade comercial.

- Catingal e Lajedinho, na região nordeste, Estado da Bahia; - Coxim, na região centro-oeste, Estado do Mato Grosso do Sul, com produção de safiras azul e amarela.

- Peixe, na região norte, Estado do Tocantins.

Exceto Peixe e Catingal, os depósitos são secundários e não apresentam resquícios da rocha original hospedeira do coríndon. As ocorrências de Palmeiras, Indaiá, Sapucaia e Caputira, localizadas na porção leste de Minas Gerais, são próximas entre si e pertecem a contextos geológicos semelhantes, em terrenos metamórficos de alto grau, compostos de gnaisses, granulitos e enderbitos (Liccardo 1999; Campos 1999, Liccardo \& JordtEvangelista 2000, Liccardo et al. 2005). A ocorrência de Campo Belo, no centro-sul de Minas Gerais, também encontra-se em aluviões sobre rochas granulíticas, com presença de corpos ultramáficos (Liccardo \& Jordt-Evangelista 2001). Em Malacacheta, centro-norte do estado, safiras são encontradas em aluviões associados a terrenos altamente intemperizados, sem afloramentos de rochas encaixantes. No contexto regional as rochas são metamórficas de médio a alto grau com presença de corpos graníticos e metaultramáficas (Basílio 1999).

Barra Velha, ao norte de Santa Catarina, o coríndon encontra-se em fácies proximais de sedimentos recentes que ocupam vastas planícies aluvionares. Esses depósitos têm sua origem associada a complexos de rochas granulíticas predominantes na região e/ou a eventos metassomáticos. (Chodur 1997; Chodur \& 


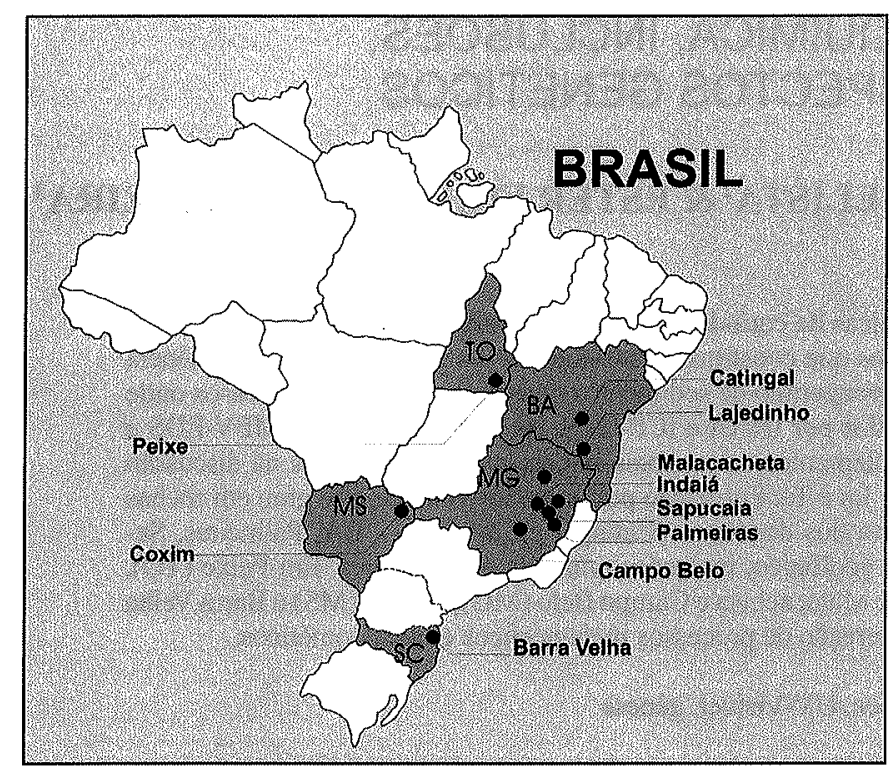

Figura 1 - Mapa do Brasil com a localização das ocorrências de corindon estudadas.

Liccardo 2000; Liccardo \& Chodur 2006).

Em Lajedinho, sul do Estado da Bahia, o coríndon encontrase em depósitos sedimentares recentes associados gneisses de fácies granulito. Na porção central do Estado, na localidade de Catingal, o mineral ocorre como porfiroblastos em paragnaisses de fácies granulito e de protólito pelítico (Jordt-Evangelista \& Liccardo 2002). A paragênese mineral é coríndon, álcali-feldspato, plagioclásio, biotita e sillimanita. Essa é uma das poucas ocorrências em que o coríndon é encontrado em rocha inalterada, sendo a outra a do Rio do Peixe (sul de Tocantins), onde encontram-se cristais centimétricos de coríndon em pegmatitos associados a complexos alcalinos (biotita-nefelina sienito e diorito). O pegmatito é pouco diferenciado e apresenta $75 \%$ em volume de oligoclásio, $10 \%$ de Fe-biotita e 10\% de coríndon. Piroxênio, moscovita, allanita e zircão perfazem 5\% (Kitajima 2002).

Em Coxim, leste do Mato Grosso do Sul, o coríndon é encontrado nos depósitos aluvionares como mineral-satélite em minerações de diamante: Não existem evidências que possam indicar possíveis rochas encaixantes, ocorrendo regionalmente somente rochas sedimentares, que poderiam conter tanto o coríndon quanto o diamante (Liccardo \& Addad 2001).

O objetivo deste trabalho é o estudo do coríndon de onze ocorrências brasileiras por meio da sua caracterização mineralógica e composicional para interpretação da gênese e obtenção de um conjunto de dados constituindo uma "assinatura" que possibilite identificar a procedência de amostras desconhecidas.

METODOLOGIA As amostras de coríndon foram obtidas por coleta sistemática, através de peneiramento e concentração, nos depósitos aluvionares e coluvionares, à exceção de Catingal e Peixe, onde o coríndon é encontrado também em rocha matriz. Selecionaram-se amostras com a coloração típica do coríndon de cada ocorrência, ou seja: safiras de coloração violeta de Sapucaia e Indaiá; safiras rosa a rosa-castanho de Palmeiras, Caputira, Barra Velha e Lajedinho; safiras azuis de Campo Belo, Malacacheta, Coxim e Peixe; safiras castanho-esverdeadas de Catingal. Devido à presença de inclusões, cristais com transparência são raros, o que limitou a quantidade de material apropriado para as análises. Cinco amostras de cada ocorrência, à exceção de Coxim ( 3 amostras) e Peixe ( 2 amostras), foram utilizadas para análises químicas por INAA. Apenas uma de cada foi destinada à análise química por ICP. Para estudo de inclusões por microscopia eletrônica de varredura (MEV) e espectroscopia no UV-Visível foram preparadas dez lâminas do material de cada ocorrência, exceto Coxim (3 lâminas) e Peixe (2 lâminas).

INAA: Para a determinação dos teores de elementos traços, foi aplicada a Análise por Ativação Neutrônica Instrumental (INAA), utilizando-se o método paramétrico $\left(\kappa_{0}\right)$. A preparação do material visou a máxima purificação das amostras, procurando-se eliminar as grandes inclusões. Inicialmente as amostras foram pulverizadas em uma granulometria de aproximadamente 100 mesh, utilizando-se graal de diamonite. Em seguida foram lavadas com ácido fluorídrico concentrado e depois imersas em uma solução de ácido nítrico, ácido perclórico e ácido sulfúri$\mathrm{co}$, na qual foi gotejado peróxido de hidrogênio. Posteriormente o material resultante foi separado por diferença de densidade, utilizando-se bromofórmio. Enfim foi lavado com uma solução diluída de $\mathrm{NH}_{4} \mathrm{OH}$ e ainda, com uma mistura de álcool, acetona e água destilada. As amostras de coríndon, padrões e materiais de referência certificados foram irradiados no reator TRIGA MARK-I IPR-R1 (CDTN/CNEN, Centro de Desenvolvimen-to de Tecnologia Nuclear, de Belo Horizonte, MG), em uma mesa giratória, em torno do núcleo do reator sob um fluxo de nêutrons térmicos uniforme de $6,6 \times 10^{11} \mathrm{ncm}^{-2} \mathrm{~s}^{-1}$. As análises foram acompanhadas de soluções padrões multielementares de Terras Raras, tório e materiais de referência certificados. Foram utilizados como referência padrões geológicos USGS (United States Geological Survey): GXR-5 e IAEA (International Ato-mic Energy Agency): Soil-1, Soil-3, Soil-7. Todas as amostras de coríndon, padrões e materiais de referência certificados foram pesados com uma massa de $0,3000 \mathrm{~g}$ e acondicionados em tubos de irradiação adequados. Essa técnica é apropriada para a quantificação de elementos traços, com resultados excepcionais para elementos Terras Raras.

Os limites de detecção para os elementos analisados são: $\mathrm{Cr}$ $300 \mathrm{ppb}, \mathrm{Fe} 4000 \mathrm{ppb}$, Ga 72ppb, Na 9ppb, Tb 15ppb, Th 12ppb, Ce 300ppb, La 20ppb, W 34ppb, As 45ppb, Ta $11 \mathrm{ppb}$, Sb 2ppb, $\mathrm{Sc} 1 \mathrm{ppb}$, Co $1 \mathrm{ppb}$. Na investigação dos elementos de meia-vida curta o tempo de irradiação foi de $5 \mathrm{~min}$, de espera $15 \mathrm{~min}$ e de contagem 600 s. Para os elementos de meia-vida média o tempo de irradiação foi de 4 horas, de espera 12 horas e de contagem 1 hora. Para os de meia-vida longa o tempo de irradiação foi de 16 horas, de espera 30 dias e de contagem 3 horas.Os espectros gama foram medidos em um detector HPGe ORTEC modelo 10175-P, FWHM de $1,85 \mathrm{keV}$ para a energia de $1332 \mathrm{keV}$ do $60 \mathrm{Co}$, acoplado a microcomputador por eletrônica apropriada/ Maestro II. Os principais elementos investigados foram: Dy, Ba, $\mathrm{Ti}, \mathrm{As}, \mathrm{Mg}, \mathrm{V}, \mathrm{Al}, \mathrm{Mn}, \mathrm{Cu}, \mathrm{Cl}$ (radionuclídeos meia-vida curta); $\mathrm{W}, \mathrm{Na}, \mathrm{La}, \mathrm{Au}, \mathrm{Ga}, \mathrm{As}, \mathrm{K}$, Th, U (radionuclídeos de meia-vida média); Ce, Tb, Cr, Zn, Sc, Sr, Sb, Cs, Sc, Rb, Fe, Co, Ta, Ag, $\mathrm{Eu}, \mathrm{Tb}$ (radionuclídeos de meia-vida longa). No entanto, somente para 14 dos citados elementos (Tabela 1) os teores estão acima do limite de deteç̧ão nas amostras investigadas.

ICP/OES: Análises químicas por ICP/OES (Plasma Indutivamente Acoplado com Espectrometria e Emissão Óptica) foram realizadas num equipamento Perkin-Elmer Optima 3000, em leitura direta, utilizando os procedimentos do laboratório Lakefield-Geosol, de Belo Horizonte (MG). Foram analisados os elementos Ti, Mn e V para complementar as análises por INAA. A moagem do material foi realizada em moinho de esfera de cerâmica, evitando-se a contaminação por metais. Do pó obtido (cerca de 300 mesh) foram pesados $500 \mathrm{mg}$, que foram fundidos juntamente com $5 \mathrm{~g}$ de tetraborato de lítio à temperatura de $1000^{\circ} \mathrm{C}$, em cadinho de platina. $\mathrm{O}$ material resultante foi dissolvido em $200 \mathrm{ml}$ de água com $5 \mathrm{ml} \mathrm{de} \mathrm{H}_{2} \mathrm{SO}_{4}$ e depois separado 
Tabela 1-Teor de elementos menores e traços (em ppm, análises por INAA) em coríndon das ocorrências brasileiras estudadas

\begin{tabular}{|c|c|c|c|c|c|c|c|c|c|c|c|c|c|c|c|}
\hline $\begin{array}{r}\text { Element } \\
\text { Incerteza ( } \% \\
\text { Amostr }\end{array}$ & & $\operatorname{Cr}(2)$ & $\mathrm{Fe}(5)$ & $\mathbf{G a}(2)$ & $\mathrm{Na}(3)$ & $\mathbf{T b}(5)$ & Th (3) & $\mathrm{Ce}(10)$ & $\mathbf{L a}(4)$ & $\mathbf{W}(10)$ & As $(10)$ & $\mathbf{T a}(2)$ & $\mathbf{S b}(9)$ & Se (3) & $\begin{array}{l}\text { Co } \\
\text { (4) }\end{array}$ \\
\hline \multirow{5}{*}{$\begin{array}{l}\text { Palmeiras } \\
\text { (rosa) }\end{array}$} & 1 & 596 & 2022 & 71 & 63 & 1 & 8 & 98 & 16 & 1 & - & - & 1 & - & - \\
\hline & 2 & 1293 & 3733 & 114 & 73 & 8 & 51 & 368 & 150 & 4 & 8 & - & 4 & - & 1 \\
\hline & 3 & 707 & 2302 & 81 & 71 & 8 & 48 & 307 & 126 & 1 & 4 & - & 4 & - & - \\
\hline & 4 & 697 & 2161 & 63 & 67 & 3 & 23 & 123 & 25 & 3 & - & - & 2 & - & - \\
\hline & 5 & 904 & 2769 & 54 & 68 & 2 & 9 & 142 & 42 & 2 & - & - & 1 & - & - \\
\hline \multirow{5}{*}{$\begin{array}{l}\text { Sapucaia } \\
\text { (violeta) }\end{array}$} & 1 & 54 & 4603 & 94 & 58 & - & - & 21 & 3 & - & - & - & - & - & - \\
\hline & 2 & 75 & 9312 & 293 & 169 & 1 & 1 & 28 & 7 & 2 & 3 & - & 5 & - & - \\
\hline & 3 & 280 & 4633 & 104 & 82 & 5 & 5 & 300 & 148 & - & - & - & - & - & 2 \\
\hline & 4 & 149 & 5700 & 142 & 95 & 1 & 1 & 150 & 206 & - & 6 & - & 1 & - & - \\
\hline & 5 & 1092 & 8302 & 183 & 130 & 4 & 4 & 300 & 15 & - & - & - & - & - & - \\
\hline \multirow{6}{*}{$\begin{array}{l}\text { Indaiá } \\
\text { (violeta) }\end{array}$} & 1 & 390 & 2626 & 93 & 78 & 3 & 29 & 145 & 81 & - & - & - & 4 & - & - \\
\hline & 2 & 215 & 2631 & 77 & 75 & 1 & 13 & 159 & 69 & - & - & - & - & - & - \\
\hline & 3 & 285 & 2500 & 65 & 64 & 2 & 18 & 81 & 46 & - & - & - & - & - & - \\
\hline & 4 & 191 & 3615 & 60 & 57 & - & 9 & 138 & 74 & - & - & - & - & - & - \\
\hline & 5 & 233 & 2714 & 57 & 71 & - & - & 66 & 19 & - & - & - & - & - & $\cdot$ \\
\hline & 1 & 3310 & 9703 & 307 & 177 & 29 & 32 & - & - & 60 & 21 & 37 & - & " & - \\
\hline \multirow{4}{*}{$\begin{array}{c}\text { Caputira } \\
\text { (verm. cast.) }\end{array}$} & 2 & 1037 & 3677 & 112 & 92 & - & - & - & - & 10 & - & 12 & - & - & - \\
\hline & 3 & 1182 & 2571 & 99 & 59 & - & - & - & 3 & 18 & 10 & 3 & 4 & 3 & - \\
\hline & 4 & 1320 & 3045 & 145 & 131 & 10 & 7 & - & - & 11 & - & 5 & - & - & - \\
\hline & 5 & 1243 & 4173 & 211 & 88 & - & - & - & - & 20 & - & 8 & - & - & - \\
\hline \multirow{5}{*}{$\begin{array}{c}\text { Campo Belo } \\
\text { (azul) }\end{array}$} & 1 & 11 & 2644 & 159 & 71 & - & 10 & - & 1 & - & - & - & 2 & - & - \\
\hline & 2 & 8 & 2713 & 97 & 67 & - & - & - & - & - & - & - & - & - & - \\
\hline & 3 & 15 & 2810 & 80 & 64 & - & - & - & - & - & - & - & - & - & - \\
\hline & 4 & 10 & 2675 & 130 & 57 & - & - & - & 2 & - & - & - & - & - & - \\
\hline & 5 & 12 & 2857 & 88 & 59 & - & - & - & - & - & - & - & - & - & - \\
\hline \multirow{5}{*}{$\begin{array}{c}\text { Malacacheta } \\
\text { (azul) }\end{array}$} & 1 & 20 & 4415 & 180 & 69 & - & 1 & - & 3 & 5 & - & 20 & - & - & - \\
\hline & 2 & 58 & 3582 & 192 & 90 & - & - & - & - & 4 & - & - & - & 7 & - \\
\hline & 3 & 25 & 3847 & 187 & 64 & - & - & - & - & 7 & - & - & - & - & - \\
\hline & 4 & 32 & 4132 & 183 & 71 & - & - & - & - & 12 & - & - & - & - & $\cdot$ \\
\hline & 5 & 40 & 4214 & 190 & 67 & - & - & - & - & 9 & - & - & - & - & - \\
\hline \multirow{4}{*}{$\begin{array}{l}\text { Coxim } \\
\text { (azul) }\end{array}$} & 1 & 8 & 6340 & 156 & 64 & - & - & - & - & - & - & 2 & - & - & - \\
\hline & 2 & 1 & 4572 & 148 & 68 & - & 1 & - & - & - & - & - & - & - & - \\
\hline & 3 & 9 & 4887 & 152 & 71 & - & - & - & - & - & - & - & - & - & - \\
\hline & 1 & 75 & 9439 & 95 & 64 & 1 & 10 & 31 & 14 & 6 & - & - & 3 & - & - \\
\hline \multirow{4}{*}{$\begin{array}{c}\text { Catingal } \\
\text { (verde cast.) }\end{array}$} & 2 & 81 & 12766 & 113 & 75 & - & 2 & 109 & 46 & - & - & 1 & - & - & - \\
\hline & 3 & 146 & 11963 & 138 & 107 & 5 & 41 & 70 & 129 & - & - & - & - & - & - \\
\hline & 4 & 94 & 10131 & 98 & 87 & - & 13 & 47 & 23 & - & - & - & - & - & - \\
\hline & 5 & 103 & 11317 & 110 & 95 & - & 25 & 98 & 85 & - & - & - & - & - & - \\
\hline \multirow{5}{*}{$\begin{array}{c}\text { Lajedinho } \\
\text { (rosa) }\end{array}$} & 1 & 547 & 637 & 25 & 135 & - & - & - & - & - & - & - & - & - & - \\
\hline & 2 & 886 & 863 & 29 & 80 & - & - & - & - & - & - & $\sim$ & - & - & - \\
\hline & 3 & 614 & 717 & 27 & 119 & - & - & - & - & - & - & - & - & - & - \\
\hline & 4 & 735 & 685 & 29 & 98 & - & - & - & - & - & - & - & - & - & - \\
\hline & 5 & 669 & 787 & 27 & 107 & - & - & - & - & - & - & - & - & - & - \\
\hline \multirow{5}{*}{$\begin{array}{c}1 \\
\text { Barra Velha } \\
\text { (rosa) } \\
5\end{array}$} & 1 & 941 & 4239 & 89 & 85 & - & - & - & 4 & - & - & - & - & - & - \\
\hline & 2 & 515 & 2036 & 103 & 80 & - & - & - & 2 & - & " & - & - & - & - \\
\hline & 3 & 3456 & 3581 & 70 & 124 & - & 3 & - & 3 & - & - & - & - & - & - \\
\hline & 4 & 835 & 4060 & 95 & 96 & - & - & - & 2 & - & - & - & - & - & - \\
\hline & 5 & 307 & 3875 & 87 & 88 & - & 1 & - & 3 & - & - & - & - & - & - \\
\hline Peixe & 1 & 2 & 1061 & 148 & 70 & - & - & - & - & - & - & 1 & - & - & - \\
\hline (cinza azul) 2 & & 3 & 1458 & 165 & 82 & 1 & 5 & 33 & - & - & - & - & - & - & - \\
\hline
\end{tabular}

* Valores com hífen abaixo do limite de detecção 
Tabela 2 - Teor de Ti, Mn e V (em ppm, análises por ICP-OES) em coríndon das ocorrências brasileiras estudadas

\begin{tabular}{l|ccc}
\hline & $\mathrm{Ti}$ & $\mathrm{Mn}$ & $\mathrm{V}$ \\
\hline Palmeiras (rosa) & 172 & 9 & 57 \\
Sapucaia (violeta) & 361 & 18 & 62 \\
Indaiá (violeta) & 185 & 13 & 44 \\
Caputira (verm.cast.) & 21.480 & 13 & 106 \\
Campo Belo (azul) & 75 & 18 & 13 \\
Malacacheta (azul) & 392 & 13 & 18 \\
Coxim (azul) & 405 & 13 & 13 \\
Catingal (verde-cast.) & 158 & 22 & 22 \\
Lajedinho (rosa) & 75 & 35 & 9 \\
Barra Velha (rosa) & 216 & 35 & 35 \\
Peixe (cinza-azulado) & 97 & 18 & 13 \\
\hline
\end{tabular}

em volumes de $200 \mathrm{ml}$

MEV/EDS: Para a análise e identificação das inclusões sólidas do coríndon, foi utilizada a Microscopia Eletrônica de Varredura com Espectrometria de Energia Dispersiva (MEV/EDS). Foi utilizado equipamento Philips, modelo XL-30 com dispositivo EDAX - DXY para a detecção de elementos leves, do LAC- Laboratório Central de Pesquisa e Desenvolvimento, na Universidade Federal do Paraná, em Curitiba, PR. A tensão do feixe de elétrons variou de 15 a $20 \mathrm{kV}$ e o vácuo foi de $4 \times 10^{-6}$ mbar. O vácuo para metalização das amostras foi de $10^{-3} \mathrm{mbar}$. Os cristais de coríndon foram cortados em pequenas chapas padronizadas com $2 \mathrm{~mm}$ de diâmetro, cortadas perpendicularmente ao eixo c.

Espectroscopia : Para a espectroscopia UV-Visível foi utilizado um equipamento Hewlett-Packard, Diode Array, modelo 8452A, no Laboratório de Química da Universidade Federal do Paraná, em Curitiba (PR), calibrado com ar (branco), tempo de integração de 1 segundo e aquisição entre 190 e $820 \mathrm{~nm}$. Os espectros visam obter uma assinatura característica para cada material, além de revelar possíveis mecanismos ou elementos causadores de cor.

\section{RESULTADOS}

3.1 Química A técnica de INAA, apesar de fornecer resultados muito acurados para múltiplos elementos, não é capaz de determinar teores de certos elementos como $\mathrm{Ti}$, que tem importante papel na causa de cor, em função da sobreposição de espectros. Portanto, análises em ICP-OES foram realizadas para Ti, Mn e V, com a finalidade de complementar a caracterização química efetuada com o método INAA. Os resultados das análises de elementos menores e traços por INAA são apresentados na Tabela 1 e os resultados por ICP, na Tabela 2.

O Fe é o elemento com maior concentração. Os teores mais altos foram encontrados em Catingal e Sapucaia (respectivamente 11.123 e $6.510 \mathrm{ppm}$, em média) e os mais baixos em Lajedinho e Peixe (738 e 1.260ppm, em média). Os demais depósitos apresentam valores intermediários variando entre $2.740 \mathrm{ppm}$ em média para Campo Belo e 5.266ppm para Coxim.

Verifica-se que $\mathrm{Cr}$ é mais baixo nas amostras de cor azulada

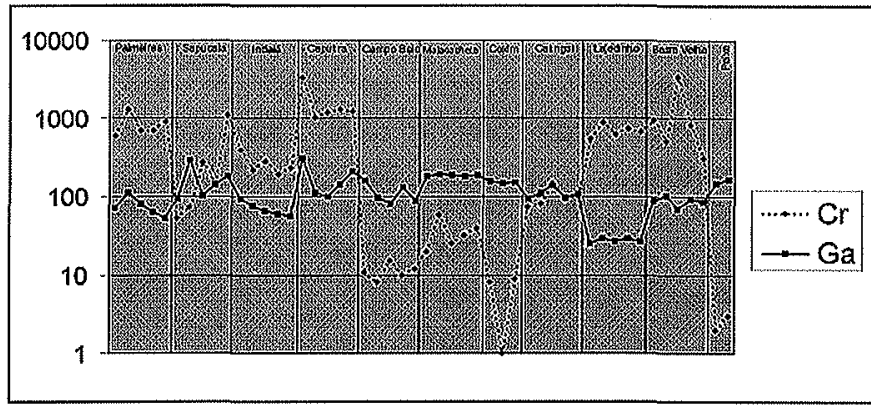

Figura 2 - Variação de Cr e Ga para as amostras de coríndon das ocorrências estudadas (em ppm)

(Campo Belo, Malacacheta, Coxim, Peixe: 1 a 58ppm ) e mais alto nas variedade de cor rosa ou avermelhada (Lajedinho: 690ppm em média, Palmeiras: 839ppm, Barra Velha: $1.210 \mathrm{ppm}$ e Caputira: $1.618 \mathrm{ppm})$. Valores intermediários foram encontrados em amostras de cor violeta (Sapucaia e Indaiá: médias de 330 e 263ppm, respectivamente) e de cor esverdeada (Catingal: $100 \mathrm{ppm}$ ). A Figura 2 mostra a variação de $\mathrm{Cr}$ e de $\mathrm{Ga}$, considerados como importantes indicadores de ambiente genético (Sutherland \& Schwarz 2001), para as ocorrências estudadas. Os teores de $\mathrm{Cr}$ apresentam maior variação, inclusive entre as amostras de uma mesma localidade, como, por exemplo, em Coxim e Sapucaia.

O teor de Ga (Tabela 1 e Figura 2) é menos variável do que o de Cr. Em Malacacheta, Coxim e Lajedinho o Ga é bastante uniforme para todas as amostras e, particularmente em Lajedinho, o teor é menor do que nas outras localidades (em torno de $27 \mathrm{ppm}$ ), podendo ser considerado como bom um indicador de procedência.

Os resultados para o $\mathrm{Ti}$ (Tabela 2) mostram uma anomalia em Caputira, com 21.480ppm em comparação com a variação de 75 a 405ppm para as demais ocorrências. É possível que não se tenha conseguido eliminar por completo parte das inúmeras inclusões de rutilo na preparação da amostra de Caputira para análise por ICP.

O Na aparece em todas as amostras, exibindo certa constância (57-177ppm). Mn (Tabela 2) também não mostra grande variação. O V é o mais alto em Caputira (106ppm) e o mais baixo em Lajedinho (9ppm).

Em relação aos elementos Terras Raras e ao Th, Palmeiras, Sapucaia, Indaiá e Catingal apresentam teores relativamente elevados, especialmente de Ce (até 368ppm em Palmeiras) e La (até 206ppm em Sapucaia). Em Barra Velha apenas o La foi encontrado em todas as amostras, porém em teor consideravelmente menor do que nos depósitos citados. Nos demais, esses elementos estão ausentes ou ocorrem em teores baixos em somente poucas amostras. Em Caputira duas amostras apresentaram Th e Tb. Caputira apresenta semelhanças com Malacacheta em termos de um teor mais elevado de $\mathrm{W}$, mas se distingue por conter também $\mathrm{Ta}$, que só aparece em uma única amostra de Malacacheta. $\mathrm{Sb}$ aparece em teores baixos, de 1 a $5 \mathrm{ppm}$, em todas as amostras de Palmeiras e em duas de Sapucaia. Nas outras ocorrências aparece em raras amostras. Os demais elementos da Tabela $1(\mathrm{Co}, \mathrm{Sc}, \mathrm{As})$ ocorrem em poucas amostras e não chegam a constituir uma característica química particular.

\subsection{Espectroscopia UV-Visível}

Os espectros de absorção na faixa do UV-Visível de amostras com a típica cor de cada ocorrência são apresentados na Figura 3. Além de ser uma ferramenta auxiliar como indicador de procedência, a análise dos espectros pode fornecer indicações quanto à causa da cor na amostra. Os elementos cromóforos 
no coríndon são $\mathrm{Cr}$ (causador da cor vermelha no rubi), $\mathrm{Fe}$ (responsável pela indesejada cor acastanhada) e Ti, o qual, em conjunto com $\mathrm{Fe}$, produz a cor azul de safiras em virtude da transferência de carga $\mathrm{Fe}^{2+}-\mathrm{Ti}^{4+}$ (Hughes 1990). No entanto, diferentes estados de valência podem causar variação na cor e, portanto, somente a análise do teor de um elemento não é
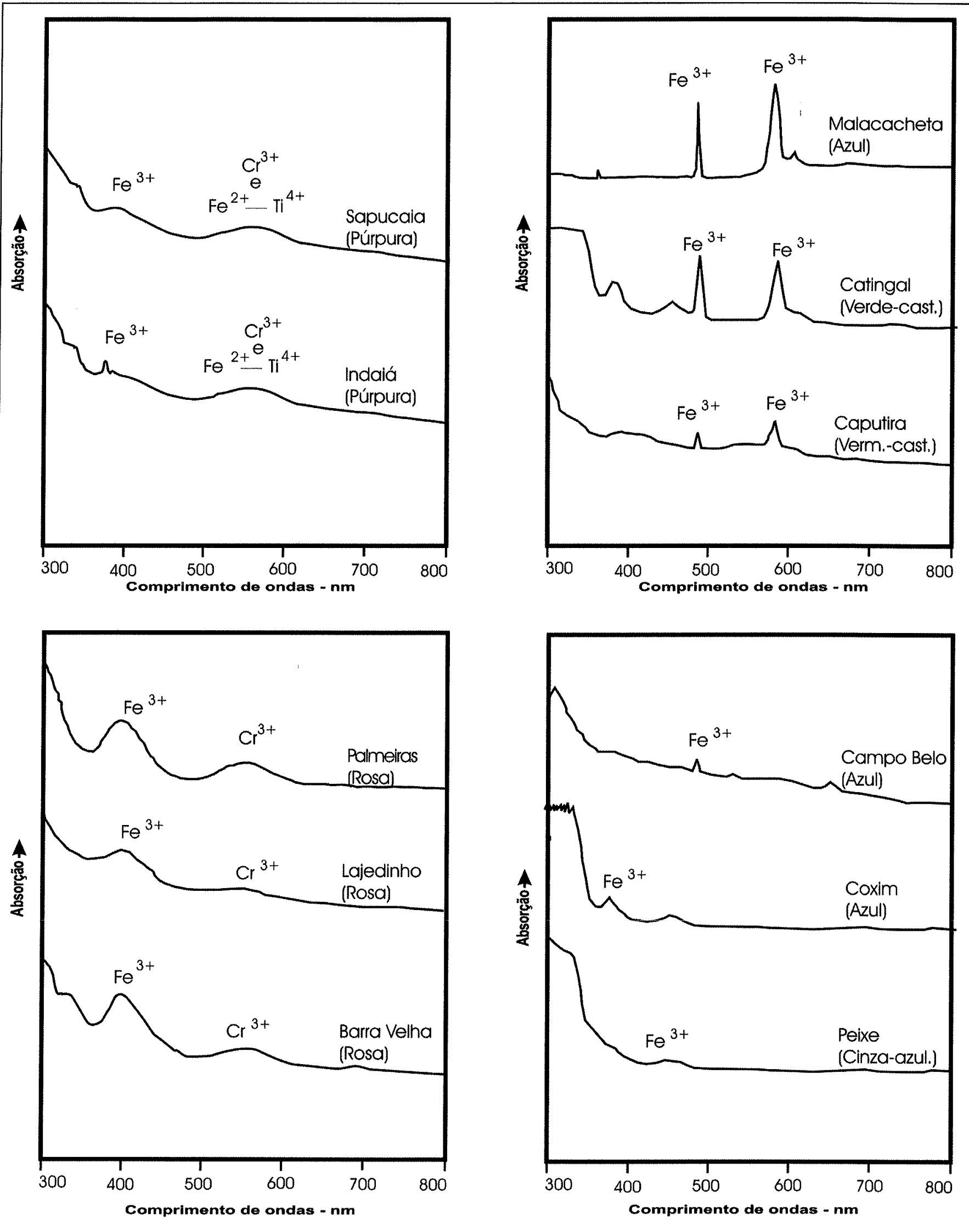

Figura 3-Espectros de absorção em UV-Visivel de amostras selecionadas de rubi e safiras das ocorrências estudadas 
suficiente para afirmar ser ou não o mesmo o responsável por uma determinada tonalidade.

Verifica-se que os espectros de Sapucaia e Indaiá, de coríndon de cor violeta, são semelhantes, mostrando uma banda de absorção entre 370 e 420nm, que em safiras azuis do Sri Lanka, Mianmar, Vietnam e outras, é associada à presença de $\mathrm{Fe}^{3+}$ (Smith et al., 1995). Uma outra banda mais larga, entre $500 \mathrm{e}$ $600 \mathrm{~nm}$, pode ser causada pelo mecanismo de transferência de carga $\mathrm{Fe}^{2+}-\mathrm{Ti}^{4+}$ (considerado responsável pela cor azul) ou por $\mathrm{Cr}^{3+}$ (responsável pela cor vermelha). Como a cor violeta é a superposição de vermelho e azul, estes dois mecanismos podem estar atuando neste caso.

Para as amostras de cor rosa (Palmeiras, Lajedinho e Barra Velha) os espectros mostram a banda entre 370-420nm, atribuída ao $\mathrm{Fe}^{3+}$, bastante pronunciada. A banda entre 500 e $600 \mathrm{~nm}$ é atribuída, neste caso, a $\mathrm{Cr}^{3+}$ (responsável pela tonalidade vermelha), o que se justifica pela ausência do componente azul na cor destas amostras. $\mathrm{O}$ teor relativamente elevado de $\mathrm{Cr}$ nestas amostras (variando, em média, de 690 a $1.210 \mathrm{ppm}$ ), quando comparado com Indaiá e Sapucaia (em torno de 300ppm, em média, Tabela 1), corrobora esta interpretação.

Nas amostras de cor azul (Campo Belo, Coxim e Peixe) o baixo teor de $\mathrm{Cr}$ ( 1 a $15 \mathrm{ppm}$ ) indica que o mecanismo causador das incipientes bandas de absorção pode ser atribuído ao Fe que é o elemento-traço mais abundante (em média, $1.260 \mathrm{a}$ $5.266 \mathrm{ppm}$ ). A participação de Ti na causa de cor é improvável, pois é relativamente baixo em duas das amostras (Campo Belo: $75 \mathrm{ppm}$ em média, Peixe : 97ppm), sugerindo uma causa do tipo transferência de carga entre $\mathrm{Fe}^{2+} \mathrm{e} \mathrm{Fe}^{3+}$.

Os espectros de absorção de Malacacheta, Catingal e Caputira distinguem-se por dois pronunciados picos de absorção a 485 e 585nm, que na literatura (Smith et al. 1985) costumam ser atribuídos a $\mathrm{Fe}^{3+}$. Em Malacacheta, a cor azul pode ser decorrente do mecanismo $\mathrm{Fe}^{2+}-\mathrm{Ti}^{\circ+}$, já que as análises químicas apontaram teor relativamente alto de Ti (392ppm). Em Catingal (coríndon verde-acastanhado), o Fe muito alto (em média $11.123 \mathrm{ppm}$ ) pode ser o responsável pela tonalidade acastanhada. Em Caputira, a cor vermelho-acastanhada pode ser resultante da associação do $\mathrm{Cr}$ relativamente mais alto (média de $1.618 \mathrm{ppm}$ ) com o teor alto de Fe (média de $4.634 \mathrm{ppm}$ ).

3.3 MEV/EDS Inclusões sólidas referem-se a diminutos cris- tais de natureza variada englobados pelo mineral durante sua cristalização. Sua identificação é de grande interesse, pois a paragênese encontrada pode ser utilizada para identificar a rocha fonte, os processos envolvendo a formação do hospedeiro e, em alguns casos, outros fenômenos a que o mineral foi submetido após sua cristalização. As principais fases sólidas identificadas nas amostras analisadas estão relacionadas na Tabela 3.

Mineral comum como inclusão em coríndon, o rutilo costuma ser o principal responsável pelos diferentes graus de transparência desse mineral, além de proporcionar efeitos ópticos especiais em rubi e safiras (asterismo, efeito seda e chatoyance). A maior parte das amostras analisadas contém rutilo. Nas safiras de Palmeiras, Sapucaia, Indaiá e Caputira essas inclusões tendem a se apresentar na forma de grãos arredondados, principalmente nessa última. Nas outras amostras estão na forma de agulhas muito finas e alongadas. Não foi encontrado rutilo em amostras de Campo Belo, Malacacheta, Catingal e Peixe. Ilmenita, outro mineral de Ti, ocorre em Palmeiras, Sapucaia, Indaiá Malacacheta e Coxim.

Também comum em coríndon, o diásporo é uma das fases hidratadas de $\mathrm{Al}_{2} \mathrm{O}_{3} \mathrm{e}$, à semelhança do rutilo, costuma ocasionar perda de transparência em rubi e safiras por se apresentar preenchendo planos paralelos da geminação polissintética. Chodur (1997) mostrou ser o diásporo o causador dos efeitos ópticos especiais (efeito seda e asterismo) encontrados em rubis e safiras de Barra Velha, preenchendo canalículos paralelos entre si. Liccardo et al. (2000) encontraram diásporo e outras fases hidratadas de $\mathrm{Al}_{2} \mathrm{O}_{3}$ em grande parte do coríndon das ocorrências de Minas $\mathrm{Ge}-$ rais. Essas fases não são facilmente detectáveis em MEV/EDS devido ao pouco contraste com a matriz de coríndon.

Nas amostras de Indaiá, Sapucaia e Malacacheta foram encontradas inclusões de $\mathrm{Al}_{2} \mathrm{SiO}_{5}$. A técnica do MEV/EDS fornece a composição química, mas não as características estruturais do mineral, o que não permite distinguir qual dos polimorfos (cianita, sillimanita ou andaluzita) está presente. Entretanto, a presença de qualquer desses polimorfos aponta para importantes considerações genéticas, já que eles são minerais típicos de rochas metamórficas aluminosas. Inclusões de hercinita (espinélio de $\mathrm{Al}$ e $\mathrm{Fe}$ ), típica de fácies granulito, foram detectadas nas safiras de Indaiá, o que associado à presença de polimorfo de $\mathrm{Al}_{2} \mathrm{SiO}_{5}$, fornece importantes informações sobre o grau metamórfico e protólito da rocha portadora do coríndon e, por conseguinte, sobre as

Tabela 3-Inclusões sólidas identificadas por MEVIEDS em coríndon das ocorrências estudadas

\begin{tabular}{l|l}
\hline Ocorrência & Inclusões sólidas \\
\hline Palmeiras & Rutilo em agulha e arredondado, apatita, ilmenita, hematita, monazita, mica \\
Sapucaia & Rutilo, diásporo (secundária), ilmenita e polimorfo de $\mathrm{Al}_{2} \mathrm{SiO}_{5}$ \\
Indaiá & Rutilo, ilmenita, polimorfo de $\mathrm{Al}_{2} \mathrm{SiO}_{5}$, monazita, espinélio \\
Caputira & Rutilo muito abundante e arredondado, zircão e diásporo (secundário) \\
Campo Belo & Não investigadas \\
Malacacheta & Ilmenita, polimorfo de $\mathrm{Al}_{2} \mathrm{SiO}_{5}$ \\
Coxim & Rutilo, ilmenita (raras) \\
Catingal & Zircão euédrico, monazita, hematita, mica \\
Lajedinho & Apatita, rutilo \\
Barra Velha & Biotita, monazita, rutilo, diásporo (secundário, em canais), clorita e pirita \\
Peixe & Zircão \\
\hline
\end{tabular}




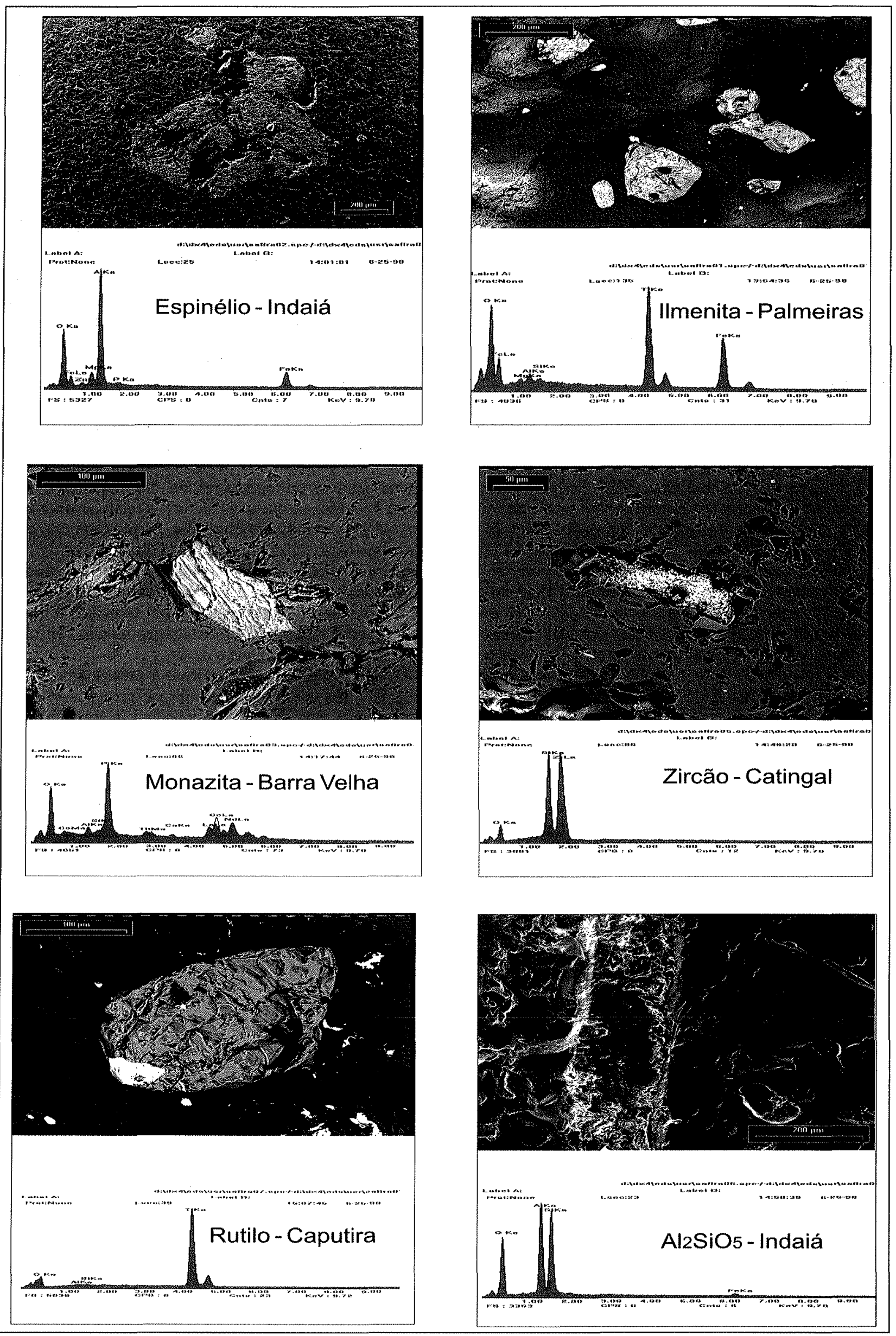

Figura 4-Imagens de MEV/EDS de inclusões selecionadas do corindon das ocorrências investigadas. 
condições de origem deste mineral. Zircão, em geral euédrico, é encontrado com frequência nas amostras de Catingal, Caputira, Indaiá, Peixe e Palmeiras. Monazita foi identificada somente nas amostras de Palmeiras, Indaiá, Catingal e Barra Velha. Possivelmente a presença deste mineral pode ter influenciado nos teores de elementos Terras Raras nas análises químicas (Tabela 1). Somente em Barra Velha foram identificadas inclusões de pirita e clorita que, em consonância com os estudos de Chodur (1997), podem ser utilizadas como fator diagnóstico de procedência em relação às outras amostras estudadas. Ambos minerais são relativamente abundantes nos rubis e safiras desse depósito. Foram constatadas, ainda, inclusões de micas e hematita (ou magnetita) no coríndon de Catingal e Palmeiras. No caso de Catingal o mineral de ferro é muito abundante, o que exerce forte influência sobre os teores de Fe obtidos nas análises químicas. Mica também ocorre inclusa nos cristais de Indaiá e Sapucaia. Somente em Palmeiras e Lajedinho foi encontrada apatita inclusa em coríndon. Imagens de MEV de inclusões selecionadas são apresentadas na Figura 4.

\section{4 - DISCUSSÃO DOS RESULTADOS E CONCLUSÕES}

As causas dos picos nos espectros em UV-Visível (Fig. 3) puderam ser interpretados, em parte, com base em dados de literatura (e.g. Hughes 1990, Smith et al. 1995, Sutherland et al. 1998). Assim, nos espectros das amostras com tonalidade rosa de Palmeiras, Barra Velha e Lajedinho, nas quais o teor de $\mathrm{Cr}$ é relativamente alto ( $>637 \mathrm{ppm}$ ), a banda de absorção na faixa de 500 a $600 \mathrm{~nm}$ deve-se, provavelmente, ao ín cromóforo $\mathrm{Cr}^{3+}$, que é o responsável pelo vermelho no rubi. Também em amostras de coloração violeta (Sapucaia e Indaiá) o $\mathrm{Cr}^{3+}$ pode ter participação na geração do componente vermelho dessa cor. Por outro lado, no caso de Caputira não se observa a banda de absorção na faixa de 500 a $600 \mathrm{~nm}$, embora as amostras tenham coloração vermelho-acastanhada e elevado teor de Cr. Em relação às safiras azuis, os espectros, segundo a literatura, apresentam um banda de absorção entre 500 e $600 \mathrm{~nm}$ decorrente de transferência de carga $\mathrm{Fe}^{2+}-\mathrm{Ti}^{4+}$. No entanto, nos espectros de Malacacheta, Campo Belo, Coxim e Peixe, de amostras de coloração azulada e que mostram teor baixo de $\mathrm{Cr}(<58 \mathrm{ppm})$, não há essa banda, além disso os espectros são diferentes uns dos outros, o que pode ser decorrente da interação de diversos mecanismos causadores de cor.

As possibilidades para a geração do coríndon envolvem processos metamórficos e/ou metassomáticos como em escarnitos, magmáticos alcalinos e ainda, associado a álcali-basaltos na forma de xenólitos de origem mantélica. O processo genético pode determinar diferenças fundamentais no coríndon, bem como nas suas inclusões e/ou na composição química. Estudos de elementos traços em coríndon de outros lugares do mundo (e.g. Schwarz et al. 1996, Sutherland et al. 1998, Schwarz \& Stern 2000, Sutherland \& Schwarz 2001) correlacionam os teores de $\mathrm{Cr}, \mathrm{Ga}, \mathrm{Fe}$ e $\mathrm{Ti}$ e definem campos relacionados aos diferentes modelos genéticos. Esses autores distinguem campos diferentes para coríndon de origem basáltica e de origem metamórfica (Figura 5, diagrama esquerdo). Sutherland \& Schwarz (2001) reconhecem, no entanto, que as conclusões sobre as variações desses elementos traços são mais consistentes em coríndon de campos basálticos. Raramente os dados obtidos em coríndon metamórfico indicam se o metamorfismo é regional em sedimentos pelíticos ou metassomático. No diagrama à direita na Figura 5 verifica-se que a razão $\mathrm{Fe} / \mathrm{Ti}$ é relativamente constante para todas as ocorrências estudadas, exceto Caputira, que apresenta uma razão baixa em virtude do elevado teor de Ti. As razões $\mathrm{Cr} / \mathrm{Ga}$ variam consideravelmente, sendo que as amostras com razões baixas (Peixe, Coxim, Malacacheta, Campo Belo) caem próximas do campo de coríndon associado a basaltos de Schwarz et al. (2000, Fig. 5). Nestas ocorrências verifica-se que o teor de $\mathrm{Ga}$ é maior do que o de $\mathrm{Cr}$.

$O$ estudo das inclusões revelou a presença de polimorfos de $\mathrm{Al}_{2} \mathrm{SiO}_{5}$ nas ocorrências de Indaiá, Sapucaia e Malacacheta, o que aponta uma gênese relacionada a metamorfismo nessas localidades. Ainda em Indaiá, foram identificadas inclusões do
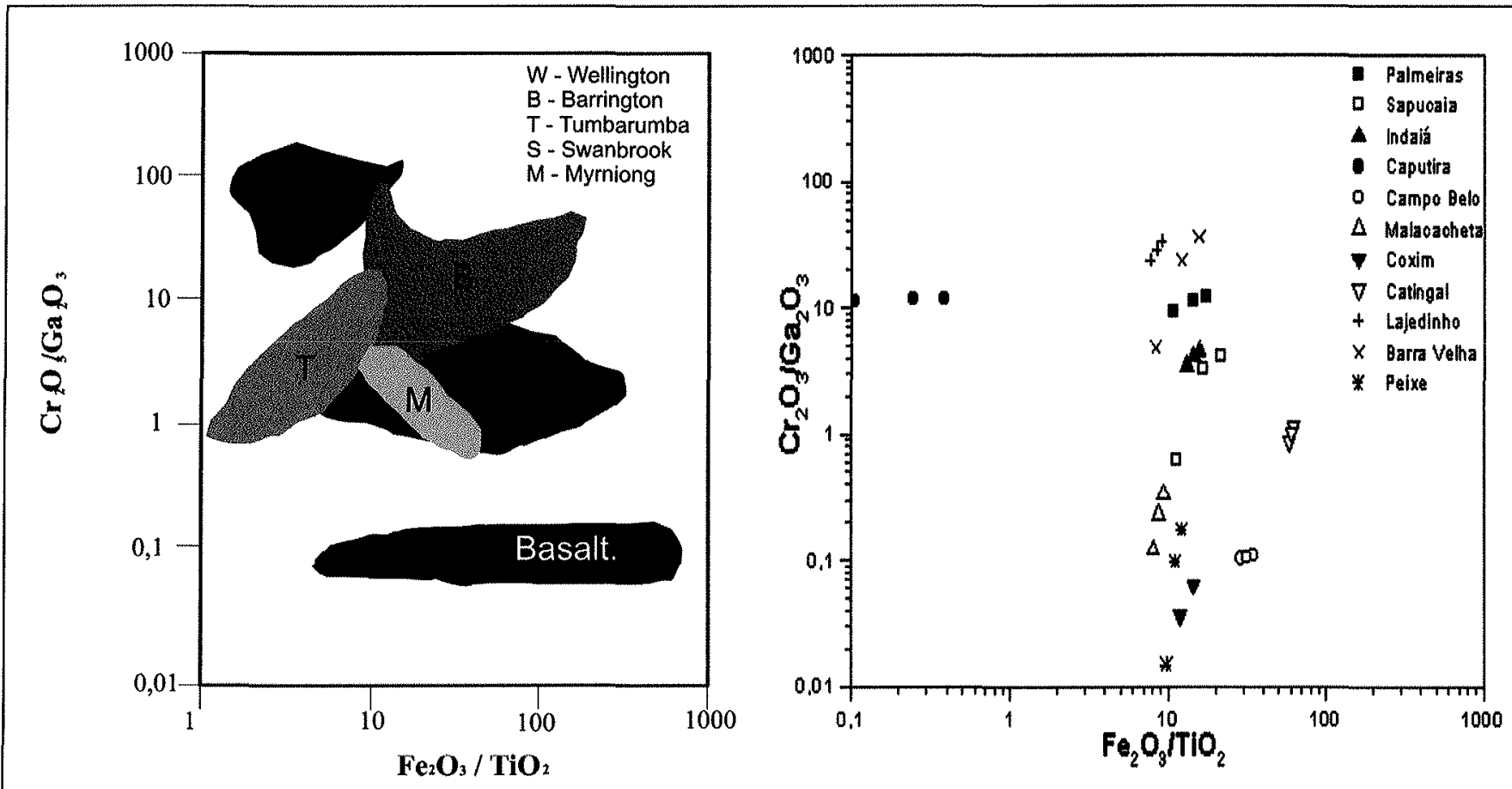

Figura 5-Correlação $\mathrm{Cr} / \mathrm{Ga}$ versus Fe/Ti em coríndon de ocorrências de origem metamórfica (campos W, T, B, Me S) e basáltica da Austrália (Schwarz et al. 2000, diagrama à esquerda) e das amostras estudadas do Brasil (à direita). 
espinélio hercinita, que é típico de condições de fácies granulito, o que condiz com o grau metamórfico de rochas da região (Liccardo 1999; Campos 1999, Liccardo \& Jordt-Evangelista 2000, Liccardo et al. 2005). Liccardo et al. (2000) sugerem para Palmeiras, Sapucaia, Caputira e Indaiá gênese metamórfica em fácies granulito, baseados em semelhanças petrogenéticas com o depósito de Catingal, onde o coríndon ocorre em paragnaisse em paragênese com álcali-feldspato, plagioclásio, biotita e sillimanita (Jordt-Evangelista \& Liccardo 2002). No depósito de Barra Velha, Chodur (1997) e Chodur \& Liccardo (2000) sugerem uma origem a partir de sedimentos pelíticos submetidos a metamorfismo de fácies granulito, em virtude de estudos geológicos e de inclusões fluidas e sólidas. Não é descartada a possibilidade de processos tectônicos terem causado a dessilicificação localizada nos granulitos, gerando coríndon por enriquecimento residual de alumínio (Liccardo \& Chodur 2006).

A presença de certos elementos traços é muito significativa nas amostras investigadas. Os teores de elementos terras raras e Th de Palmeiras, Sapucaia, Indaiá e Catingal são muito semelhantes, o que pode indicar ambiente genético e protólito semelhantes, isto é, de metamorfismo de fácies granulito de rochas quartzo-feldspáticas aluminosas, conforme comprovado em Catingal, onde o coríndon é encontrado in situ. Embora o depósito de Caputira ocorra em terrenos também granulíticos, a assinatura química em termos de Terras Raras é diferente, pois estes elementos estão praticamente ausentes. Caputira apresenta semelhanças com Malacacheta em termos de um teor mais elevado de W, o que pode significar possível influência de rochas graníticas no processo de formação do mineral. Em Malacacheta, Basílio (1999) sugere processos de metassomatismo entre corpos graníticos e ultramáficas na gênese da alexandrita encontrada junto com coríndon em aluviões e colúvios. Como em Malacacheta foram encontradas inclusões de polimorfo de $\mathrm{Al}_{2} \mathrm{SiO}_{5}$, é provável que a interação metassomática possa ter envolvido também rochas pelíticas.

A maior parte das ocorrências estudadas apresenta-se em depósitos secundários e a origem da mineralização não pode ser determinada devido à ausência de afloramentos das rochas portadoras do coríndon. $\mathrm{O}$ estudo de inclusões e elementos traços tem sido utilizado em ocorrências de outras partes do mundo na tentativa de se definir o tipo de processo que dá origem ao coríndon. A existência de duas ocorrências de coríndon em depósitos primários (Catingal e Peixe) se presta a comparativos entre esses depósitos e os outros, secundários. Rapasinghe \& Dissanayake (1985) propõem, para toda a região de charnoquitos dos Highlands no Sri Lanka, que os efeitos do metamorfismo de fácies granulito em sedimentos aluminosos representam um importante papel na formação dos depósitos de coríndon desta região. Segundo estes autores, cinturões de granulitos metassedimentares produzidos por colisão de placas são ambientes geológicos propícios para a formação de coríndon-gema. Dahanayake et al. (1980) concluíram que as fontes dos depósitos sedimentares de coríndon no Sri Lanka são gnaisses granatiferos e escarnitos. A partir disso, Munasinghe \& Dissanayake (1981) traçaram um comparativo entre estas litologias e os cinturões granulíticos metassedimentares do Brasil, descritos por Wernick \& Almeida (1979), evidenciando similaridades na história geológica e no potencial para geração de coríndon. Os resultados obtidos nas amostras de coríndon do Brasil, compilados na Tabela 4 , comprovam que a grande maioria dos depósitos pode estar associada a uma gênese em terrenos granulíticos, de maneira muito semelhante ao modelo do Sri Lanka.

Agradecimentos Ao CNPq pela bolsa de doutorado do primei-

Tabela 4 - Resumo das principais características do coríndon e considerações genéticas das ocorrências brasileiras estudadas

\begin{tabular}{|c|c|c|c|c|}
\hline & Inclusões & $\begin{array}{c}\text { Caracteristicas } \\
\text { químicas notáveis }\end{array}$ & Possível gênese & Argumentos para interpretação da gênese \\
\hline $\begin{array}{l}\text { Palmeiras } \\
\text { (rosa) }\end{array}$ & $\begin{array}{l}\text { Rutilo, apatita, ilmenita, } \\
\text { hematita, monazita, mica }\end{array}$ & $\begin{array}{l}\text { ETR* e Th altos, } \\
\text { presença de } W \text { e } \\
\mathrm{Sb}\end{array}$ & $\begin{array}{l}\text { Metamorfismo de alto grau, } \\
\text { possivel constribuição } \\
\text { metassomática de granito }\end{array}$ & $\begin{array}{l}\text { Depósito secundário encaixado em terrenos metamórficos } \\
\text { com gnaisses e granulitos; W e Sb sugerem participação de } \\
\text { granito }\end{array}$ \\
\hline $\begin{array}{l}\text { Sapucaia } \\
\text { (violeta) }\end{array}$ & $\begin{array}{l}\text { Rutilo, diásporo, ilmenita, } \\
\mathrm{Al}_{2} \mathrm{SiO}_{5}\end{array}$ & $\begin{array}{l}\text { ETR alto, Th } \\
\text { médio }\end{array}$ & $\begin{array}{l}\text { Metamorfismo de alto grau de } \\
\text { protólito pelítico }\end{array}$ & $\begin{array}{l}\text { Depósito secundário encaixado em terrenos metamórficos } \\
\text { com gnaisses e granulitos; inclusões de polimorfo de } \\
\mathrm{Al}_{2} \mathrm{SiO}_{5} \text { e espinélio }\end{array}$ \\
\hline $\begin{array}{l}\text { Indaiá } \\
\text { (violeta) }\end{array}$ & $\begin{array}{l}\text { Rutilo, ilmenita, } \mathrm{Al}_{2} \mathrm{SiO}_{5} \text {, } \\
\text { monazita, espinélio }\end{array}$ & ETR e Th altos & $\begin{array}{l}\text { Metamorfismo de fácies granulito } \\
\text { de protólito pelítico }\end{array}$ & $\begin{array}{l}\text { Depósito secundário encaixado em terrenos metamórficos } \\
\text { com gnaisses e granulitos; inclusões de polimorfo de } \\
\mathrm{Al}_{2} \mathrm{SiO}_{5}\end{array}$ \\
\hline $\begin{array}{l}\text { Caputira } \\
\text { (vermelho } \\
\text { castanho) }\end{array}$ & Rutilo, zircão, diásporo & $\begin{array}{l}\mathrm{Ti}, \mathrm{Cr}, \mathrm{Ta} \text { e W } \\
\text { altos }\end{array}$ & $\begin{array}{l}\text { Metamorfísmo de alto grau, } \\
\text { possível constribuição } \\
\text { metassomática de granito }\end{array}$ & $\begin{array}{l}\text { Depósito secundário encaixado em terrenos metamórficos } \\
\text { com gnaisses e granulitos; W e Ta sugerem participação de } \\
\text { granito }\end{array}$ \\
\hline $\begin{array}{c}\text { Campo Belo } \\
\text { (azul) }\end{array}$ & Não investigadas & Cre Ti baixos & $\begin{array}{l}\text { Incerta: metamórfica de alto grau } \\
\text { ou magmática }\end{array}$ & $\begin{array}{l}\text { Depósito secundário encaixado em terrenos granuliticos } \\
\text { favorece modelo metamorfico, mas teores muito baixos de } \\
\mathrm{Cr} \text { eTi, semelhantes a Peixe, sugerem possivel gênese } \\
\text { magmática. }\end{array}$ \\
\hline $\begin{array}{l}\text { Malacacheta } \\
\text { (azul) }\end{array}$ & Ilmenita, $\mathrm{Al}_{2} \mathrm{SiO}_{5}$ & Cr baixo, $W$ alto & $\begin{array}{l}\text { Metamorfismo metassomático } \\
\text { com interação de metapelitos e } \\
\text { granitos }\end{array}$ & $\begin{array}{l}\text { Inclusões de polimorfo de } \mathrm{Al}_{2} \mathrm{SiO}_{5} \text { indicam protólito } \\
\text { pelítico; } W \text { alto sugere participação de granito, alexandrita } \\
\text { associada nos depósitos secundários interpretada como } \\
\text { metassomática }\end{array}$ \\
\hline $\begin{array}{c}\text { Coxim } \\
\text { (azul) }\end{array}$ & Rutilo, ilmenita & Cr baixo & $\begin{array}{l}\text { Incerta: talvez associação com } \\
\text { basaltos alcalinos }\end{array}$ & $\begin{array}{l}\text { Depósito secundário encaixado em terrenos com rochas } \\
\text { sedimentares, composição química no diagrama } \mathrm{Cr} / \mathrm{Gax} \\
\mathrm{Fe} / \mathrm{Ti} \text { cai no campo de coríndon basáltico }\end{array}$ \\
\hline $\begin{array}{c}\text { Catingal } \\
\text { (verde castanho) }\end{array}$ & $\begin{array}{l}\text { Zircão, monazita, } \\
\text { hematita, mica }\end{array}$ & ETR e Th altos & $\begin{array}{l}\text { Metamorfismo de fácies granulito } \\
\text { de protólito pelítico }\end{array}$ & $\begin{array}{l}\text { Rocha hospedeira é granulito com sillimanita (depósito } \\
\text { primário) }\end{array}$ \\
\hline $\begin{array}{l}\text { Lajedinho } \\
\text { (rosa) }\end{array}$ & Rutilo, apatita & $\begin{array}{l}\text { Ti e Ga baixos, } \\
\text { ETR e Th ausentes }\end{array}$ & Metamorfismo de fácies granulito & $\begin{array}{l}\text { Depósito secundário encaixado em terreno granulítico } \\
\text { semelhante ao de Catingal }\end{array}$ \\
\hline $\begin{array}{l}\text { Barra Velha } \\
\text { (rosa) }\end{array}$ & $\begin{array}{l}\text { Rutilo, biotita, monazita, } \\
\text { diásporo, clorita, pirita }\end{array}$ & $\begin{array}{l}\text { Cr alto, presença } \\
\text { de La }\end{array}$ & $\begin{array}{l}\text { Incerta: metamorfismo } \\
\text { metassomático de alto grau } \\
\text { envolvendo gnaisses e } \\
\text { metabasitos em zonas de falhas }\end{array}$ & $\begin{array}{l}\text { Depósito secundário associado a em terrenos granulíticos, } \\
\text { com proximidade de rochas metabásicas. }\end{array}$ \\
\hline $\begin{array}{c}\text { Peixe } \\
\text { (cinza azulado) }\end{array}$ & Zircão & Cre Ti baixos & $\begin{array}{l}\text { Cristalização na fase pegmatítica } \\
\text { de magma com afinidade alcalina }\end{array}$ & $\begin{array}{l}\text { Rocha hospedeira é pegmatito associado a complexos } \\
\text { alcalinos (depósito primário) }\end{array}$ \\
\hline
\end{tabular}


ro autor, à FAPEMIG pelo financiamento parcial dos custos de campo e de análises (Projeto CEX-405/97), aos laboratórios da
UFOP, UFPR e CDTN/CNEN pelas análises.

\section{Referências}

Basílio M.S. 1999. A Alexandrita de Malacacheta, Nordeste de Minas Gerais. Dissertação de Mestrado, Departamento de Geologia, Universidade Federal de Ouro Preto, $111 \mathrm{p}$.

Campos J.C.S. 1999. Os depósitos de caulim, ametista e coríndon a NW de Manhuaçu (MG): geologia, mineralogia e gênese. Dissertação de Mestrado, Departamento de Geologia, Universidade Federal de Ouro Preto, $179 \mathrm{p}$.

Chodur N.L. 1997. Mineralogia e geologia dos depósitos de rubi e safira da região de Barra Velha, Santa Catarina. Tese de Doutoramento, Instituto de Geociências, Universidade de São Paulo, 210p.

Chodur N.L \& Liccardo A. 2000. Coríndon em terrenos granulíticos de Santa Catarina (Barra Velha) e Minas Gerais (Indaiá), Brasil. Boletim Paranaense de Geociências, 48(1):35-41.

Dahanayake K., Liyanage A. N., Ranasinghe A.P. 1980. Genesis of sedimentary gem deposits in Sri Lanka. Sediment. Geol., 25:105-115.

Hughes R.W. 1990. Corundum. Butterworth-Heinemann Ltd, London, $314 \mathrm{p}$.

Jordt-Evangelista H. \& Liccardo A. 2002. Gênese de coríndon em terrenos metamórficos de alto grau, região de Catingal, BA. In: SBG, Congr. Bras. Geol., 41, João Pessoa, Anais, p. 599.

Kitajima L.F.W. 2002. Mineralogia e Petrologia do Complexo Alcalino de Peixe, Tocantins. Tese de Doutoramento, Instituto de Geociências, Universidade de Brasília, 360p.

Liccardo A. 1999. Safiras de Indaiá, MG - Mineralogia, Geologia e Gemologia. Dissertação de Mestrado, Departamento de Geologia, Universidade Federal de Ouro Preto, 126p.

Liccardo A. \& Addad J.E. 2001. As safiras nos depósitos de diamante aluvionar da região do Rio Coxim, Mato Grosso do Sul, Brasil. Rev. Bras. Geoc. 31:635-638.

Liccardo A \& Chodur N.L. 2006. Considerações Genéticas sobre Rubi e Safiras da Região NE de Santa Catarina. In: Congr. Bras. Geol., 43, Aracaju, Anais, no prelo.

Liccardo A. \& Jordt-Evangelista H. 2000. Ocorrências de coríndon na porção leste de Minas Gerais. Geonomos, 8:39-45.
Liccardo A. \& Jordt-Evangelista H. 2001. Coríndon. In: C. Castañeda, J. E. Addad, A. Liccardo (eds). Gemas de Minas Gerais. SBG, Belo Horizonte, p. 234-259.

Liccardo A., Oliveira E.F., Jordt-Evangelista H. 2005. Rubi e safiras de Minas Gerais, Brasil. REM: R. Esc. Minas, Ouro Preto, 58:237245.

Liccardo A., Chodur N.L., Jordt-Evangelista H., Costa G.M. 2000. Identificação de fases hidratadas em coríndon no Brasil. In: UFOP, Simp. Bras. Trat. Caract. de Gemas, 1, Ouro Preto, MG, Bol. Res., p. 36 .

Munasinghe T. \& Dissanayake C.B. 1981. The origin of gemstones of Sri Lanka. Economic Geology, 76:1216-25.

Rapasinghe M.S. \& Dissanayake C.B. 1985. Charnockites and the genesis of gem minerals. Chemical Geology, 53:1-16.

Schwarz D. \& Stern W.B. 2000. Chemical fingerprinting as a tool for the characterisation of gem corundums from different genetic environments. In: Int. Geol. Cong., 31, Rio de Janeiro, Atas, CD-ROM.

Schwarz D., Petsch E.J., Kanis J. 1996.Sapphires from Andranondambo Region, Madagascar. Gems \& Gemmology, 32:80-99.

Smith C.P., Kammerling R.C., Keller A., Peretti A., Scarratt K.V., Khoa N.G., Repetto S. 1995. Sapphires from southern Vietnam. Gems \& Gemology, 31:168-186.

Sutherland F.L. \& Schwarz D. 2001. Origin of gem corundums from basaltic fields. The Australian Gemmologist, 21:30-33.

Sutherland F.L., Schwarz D., Jobbins E.A., Coenraads R.R., Webb G. 1998. Distinctive gem corundum suites from discrete basalt fields: a comparative study of Barrington, Australia and West Pailin, Cambodia gemfields. Journal of Gemmology, 26:65-85.

Wernick E. \& Almeida F.F.M. 1979. The geotectonic environments of early Precambrian granulites in Brazil. Precambrian Research, 8:117.

Manuscrito A-1368

Revisão aceita em 11 de setembro de 2006 